\title{
A Comprehensive Study of Capacitive Loaded Resonant Converter Topologies for Charging Applications
}

\author{
Geethanjali Pandeswara ${ }^{1}$, Naresh Pasula ${ }^{2}$ \\ ${ }^{1,2}$ Department of Electrical and Electronics Engineering, VNR Vignana Jyothi Institite of Engineering and Technology, \\ JNTU-Hyderabad, Telangana, India.
}

\begin{tabular}{l} 
Article Info \\
\hline Article history: \\
Received Nov 15, 2021 \\
Revised Dec 20, 2021 \\
Accepted Dec 22, 2021 \\
\hline
\end{tabular}

\section{Keywords:}

Resonant power conversion Resonant converter topologies Capacitive loaded resonant converters

Charging applications

Constant current charging

Voltage and current gain

\begin{abstract}
Resonant converters (RCs) are perceiving global interests of the research community for its eminent contribution in design of many industrial and commercial applications. Rich literature and well-established technology is available to define the role of RCs in such applications where the load is predominantly passive and resistive. However in applications like charging, the nature of load is often interpreted as capacitive and the knowledge on how a $\mathrm{RC}$ reciprocates to such variable, non linear load is limited. Motivated by this, the paper investigates about 25 capacitive loaded resonant structures and each of them is thoroughly analyzed to evaluate various key parameters like the output current, peak input current, and current gain. A comparative study is done to categorize and organize these topologies in regard to each of the said parameters. This provides a quick overview of various resonant converter topologies and helps designers to choose a structure that may fit their application. To this base knowledge, the study is further narrowed down to find suitable topology for charging application and accordingly proposed a novel fourth-order RC topology called LA7. A hardware prototype was built to compare and validate the simulated and measured performances.
\end{abstract}

Copyright $(0) 2021$ Institute of Advanced Engineering and Science. All rights reserved.

\section{Corresponding Author:}

Name of Corresponding Author Pandeswara Geethanjali,

Department of Electrical and Electronics Engineering,

VNR Vignana Jyothi Institute of Engineering and Technology,JNTU-Hyderabad,

Hyderabad, Telangana-500090, India .

Email: geethanjali.ee623@gmail.com

\section{INTRODUCTION}

Storage based power system is becoming an indispensable technology to ensure sustained power supply to residential and commercial load round the clock. High density energy storage elements such as batteries, fuel cells and ultra-capacitors can fulfil the requirement by storing large amount of power in the form of chemical energy. However a dedicated and compatible power supply is needed to charge such high energy storage devices. Resonant power conversion is found to be one of the potential technologies in the development of such power supplies.

\subsection{Motivation}

Resonant converter (RC) is an electrical network comprising of two or more reactive elements which resonate at a specific frequency (usually a high frequency). Due to the natural resonance wave forms at higher frequency, RCs have the inherent advantages like depressing switching \& conduction losses [1], mitigating conducted noise [2], suppressing electromagnetic interference [3]. These features contribute to increased efficiency and slash the need for heavy filtering requirements, complex commutation and snubber circuits. Owing to these benefits, they are admired in many practical applications like pulsed power [4], charging [5], automotive LED drivers [6], renewable energy integration [7] and other vehicular systems [8]-[9]. In spite of 
the excellent compatibility noticed with both resistive and reactive loads, RCs are widely demonstrated for industrial applications bearing resistive load [10]-[12] and a limited resource is available [13]-[14] to study the exact dynamics when feeding a capacitive load. Thus, exploring various capacitive loaded RC (CLRC) topologies form the first objective and scope of paper.

\subsection{Overview on charging technologies}

Constant Current (CC) and Constant Voltage (CV) are the two popular methods of charging. Screening from a technical perspective, CC method is preferred over CV method of charging for its ability to sustain linearity, limit inrush current, reduce losses, improve efficiency and refrain the use of oversized thermal management system. Op-Amp [15], CMOS [16] and dual bridge [17] based power supplies are already suggested to provide constant current. However they are limited to low power ratings, do not facilitate soft switching, remain un-optimized and are less efficient. Resonant converter has the potential to overcome these difficulties and so, it is considered as an attractive alternative to provide constant current.

RCs are available in multi element structures arranged in multiple topologies and the characteristic of resonant converter differs with topology. For this reason, selection of topology is specific to the application. For instance, a two element series RC topology has good control over its gain and regulation. Therefore it is recommended for DC-DC converter \& LED driver application [18]. Another two element RC called the parallel resonant converter (PRC) offers high impedance at resonant frequency and so it is suggested for induction heating application [19]. Similar overview of other series-parallel RCs in three and four element forms is presented in [20] and [21]. It is evident that, identifying the characteristics of a RC is an essential prerequisite in selecting a topology for specific application. Hence a general study is done to judge the ability of resonant converters based on few technical attributes like

\footnotetext{
i. Reducing the magnitude of current flowing through inverter feeding the RC

ii. High current gain

iii. Ability to deliver rated current
}

Reducing current through inverter will minimize stress on inverter switches, subsidize the conduction loss, lowers the switch rating, cut down the heat sink requirement and eventually improves the inverter performance. Also, higher the amount of current pumped in to the capacitor, lower will be the charging time. Thus, high current gain will be of paramount importance while reducing the time of charging [22]-[24]. Delivering the charging current close to the design is an indication of low circulating currents resulted from topological abnormalities and is an essential quality to improve the performance of CC charger. Hence categorizing the CLRCs on basis of these parameters is considered as other scope of paper.

It is claimed that higher order RC topologies has the capability to reduce peak resonant current [25][26], fast steady state response [27], suppress voltage stress [28], sharp control and effective use of parasitic components. Hence the paper focused only the higher order RC topologies as shown in Fig.1 [29]. Various mathematical techniques are being suggested [30] to simplify the job of analyzing these complex structured higher order RC topologies. As the paper is determined to find a suitable topology for CC charging application, identifying a suitable higher-order CLRC for CC charging will be the extended scope of work. At a glance, the scope and objectives of the paper are summarized below:

a. Exploring various capacitive loaded RC topologies as shown in Fig. 1

b. Categorizing the CLRCs based on some distinctive performances (like the ability to deliver maximum current, to minimize peak current, current gain).

c. Recommending a higher order CLRC topology (LA7) for CC charging application.

First section of the paper defines the problem statement and introduces various RC topologies. Second section presents the mathematical modeling \& overview of listed topologies and recommends a specific topology for charging applications. Third section verifies the claims and findings by simulation, while section 4 validated the same through hardware prototype. Fifth section concludes and summarizes entire work presented in the paper. 

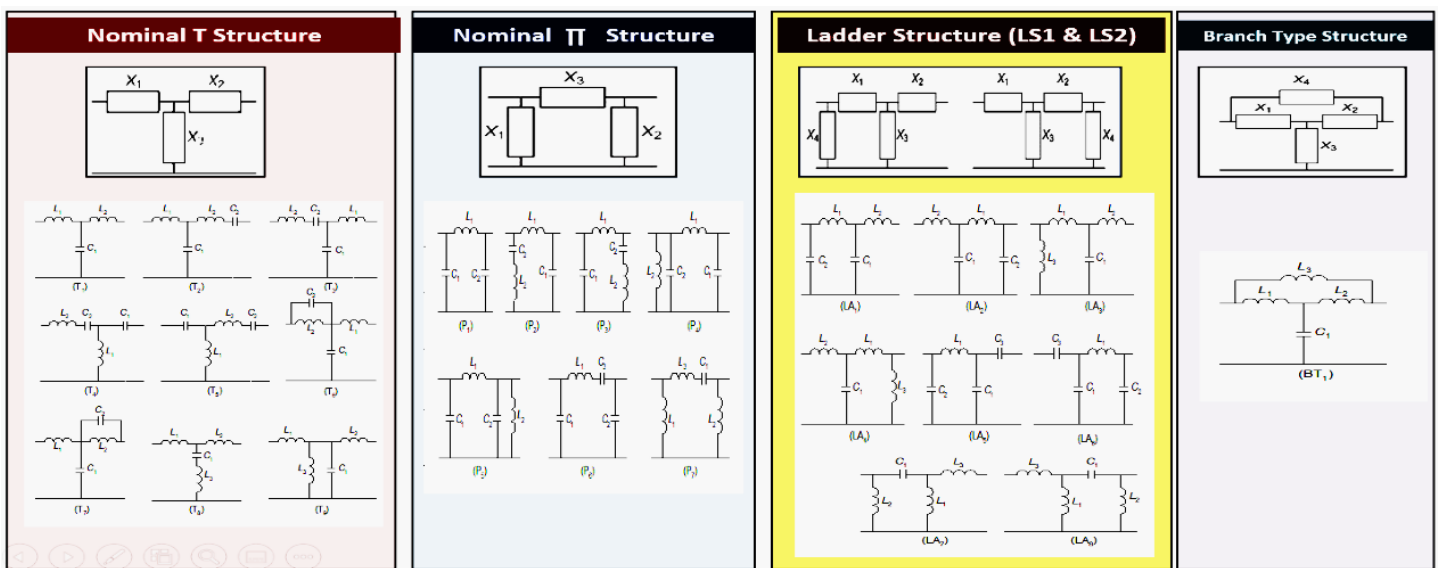

Figure 1. Capacitive loaded resonant converter topologies proposed in study

\section{MATHEMATICAL MODELLING}

This section proposes a mathematical method to model a capacitive loaded resonant converter. To demonstrate with, LA7 topology from LS1 ladder structure is chosen (on a random basis) and expressions for certain key parameters are derived in both reactance and element form. LA7 topology in its reactance and element form are shown in Fig 2(a) and 2(b). $X_{1}, X_{2}, X_{3}$ and $X_{4}$ are branch reactance corresponding to resonant capacitor $\mathrm{C} 1$ and inductors $\mathrm{L}_{3}, \mathrm{~L}_{1}, \mathrm{~L}_{2}$ of $\mathrm{LA} 7$ topology. Following notation is adhered in modeling the RC.

$\mathrm{V}_{1}, \mathrm{~V}_{2}=\mathrm{RMS}$ voltage at Input and output of RC Respectively.

$\mathrm{I}_{1}=\mathrm{RMS}$ Current flowing in to RC or Source current .

$\mathrm{I}_{2}=\mathrm{RMS}$ Current at output of RC or AC equivalent of load Current (A)

$\mathrm{Z}=$ Load impedance at Resonant Converter $(\Omega)$.

$\mathrm{M}=$ Voltage Gain $=\frac{\mathrm{V}_{2}}{\mathrm{~V}_{1}}, \mathrm{H}=$ Current Gain $=\frac{\mathrm{I}_{2}}{\mathrm{I}_{1}}, \omega_{0}=$ Resonant Frequency $(\mathrm{rad} / \mathrm{sec})$.

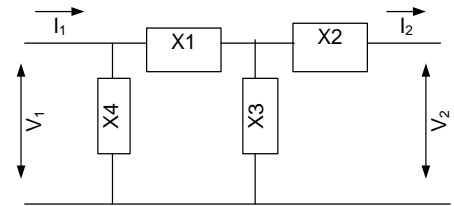

(a)

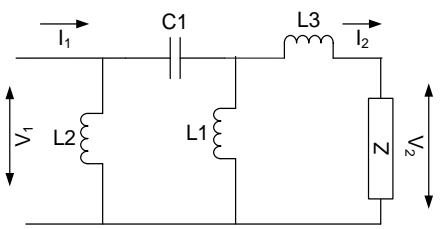

(b)

Figure 2. (a) Reactance form of LA7 topology (b) Element form of LA7 topology

i. Condition to deliver constant current: Transmission line parameters (A,B,C.D) for the ladder structured topology shown in fig 2(a) are

$$
\begin{gathered}
A=1+\frac{X_{1}}{X_{3}}, B=\frac{X_{1} X_{2}+X_{2} X_{3}+X_{3} X_{1}}{X_{3}}, C=\frac{X_{1}+X_{3}+X_{4}}{X_{3} X_{4}} ; D=-\frac{\left[X_{1} X_{2}+X_{2} X_{3}+X_{3} X_{1}+X_{4}\left(X_{2}+X_{3}\right)\right]}{X_{3} X_{4}} \\
\text { Where } X_{1}=\frac{1}{S C_{1}}, X_{2}=S L_{3}, X_{3}=S L_{1} \& X_{4}=S_{2}
\end{gathered}
$$

Condition to deliver load independent constant current ( $\mathrm{LICC}$ ) is achieved when $\mathrm{A}=\mathrm{D}=0$ and $\mathrm{BC}=1$. Under such condition, reactance of LA7 topology should be designed such that

$$
\mathrm{X}_{1}=-\mathrm{X}_{3} \text { and } \mathrm{X}_{4}=\frac{\mathrm{X}_{3}}{1-\frac{\mathrm{X}_{2}}{\mathrm{X}_{1}}}
$$

ii. Resonant Frequency $\left(\omega_{0}\right)$ : To satisfy the design criteria mentioned in equation(1), relation between resonant frequency and resonant elements should be

$$
\omega_{0}^{2}=\frac{1}{L_{1} C_{1}} \text { and } L_{1}=L_{3}=2 L_{2}
$$

Expression for current flowing in to capacitor is $i_{c}=C \frac{d_{C}}{d t}$. Hence the reactance $(Z)$ offered by capacitor is proportional to charging time $(\mathrm{t})$ and is given as $\mathrm{Z}=\frac{\mathrm{V}_{\mathrm{C}}}{\mathrm{i}_{\mathrm{c}}}=\frac{\mathrm{t}}{\mathrm{C}}$. 
iii. Voltage Gain (M): Expression for voltage gain of LA7 topology in reactance and element form is obtained by applying various circuit analysis techniques and is as followed :

$$
M=\frac{t_{3}}{\left[X_{1} X_{2}+X_{2} X_{3}+X_{3} X_{1}\right] C+t\left(X_{1}+X_{3}\right)}=\frac{t}{X_{1} C} @ L I C C \text { and } M=\frac{S^{2}\left(t_{1} C_{1}\right)}{S^{3}\left(L_{1} L_{3} C_{1} C\right)+S^{2}\left(t_{1} C_{1}\right)+S C\left(L_{1}+L_{3}\right)+t}
$$

iv. Current Gain(H): Expression for $\mathrm{H}$ of LA7 topology in reactance and element form are

$$
\mathrm{H}=\frac{\mathrm{X}_{3} \mathrm{X}_{4} \mathrm{C}}{\left[\mathrm{X}_{1} \mathrm{X}_{3}+\mathrm{X}_{2} \mathrm{X}_{4}+\mathrm{X}_{3} \mathrm{X}_{4}\right] \mathrm{C}+\mathrm{t}\left(\mathrm{X}_{4}\right)}=\frac{\mathrm{X}_{3} \mathrm{C}}{\mathrm{t}} @ \text { LICC and } \mathrm{H}=\frac{\mathrm{S}^{2}\left(\mathrm{CL}_{1} \mathrm{C}_{1}\right)}{\mathrm{S}^{2}\left(\mathrm{~L}_{1} \mathrm{C}_{1} \mathrm{C}\right)+\mathrm{S}\left(\mathrm{tC}_{1}\right)+\mathrm{C}}
$$

V. Load Current $\left(\mathrm{I}_{2}\right)$ : Expression for load current can be derived from voltage gain and is as followed

$$
I_{2}=\frac{M V_{1}}{Z}=\frac{V_{1} X_{3} C}{\left[X_{1} X_{2}+X_{2} X_{3}+X_{3} X_{1}\right] C+t\left(X_{1}+X_{3}\right)}=\frac{V_{1}}{X_{1}} @ L I C C \text { and } I_{2}=\frac{S^{2} V_{1}\left(L_{1} C_{1} C\right)}{S^{3}\left(L_{1} L_{3} C_{1} C\right)+S^{2}\left(\mathrm{tL}_{1} C_{1}\right)+S C\left(L_{1}+L_{3}\right)+t}
$$

vi. Source Current $\left(\mathrm{I}_{1}\right)$ : Expression for source current may be derived from current gain and is as followed

$$
I_{1}=\frac{V_{1}\left[X_{1} X_{3}+X_{2} X_{4}+X_{3} X_{4}+(t / C)\left(X_{4}\right)\right]}{\left[X_{1} X_{2}+X_{2} X_{3}+X_{3} X_{1}+(t / C)\left(X_{1}+X_{3}\right)\right] X_{4}}=\frac{t V_{1}}{X_{1} X_{3} C} @ L I C C \text {, and } I_{1}=\frac{V_{1}\left[S^{2}\left(L_{1} C_{1} C\right)+S\left(t C_{1}\right)+C\right]}{S^{3}\left(L_{1} L_{3} C_{1} C\right)+S^{2}\left(t_{1} C_{1}\right)+S C\left(L_{1}+L_{3}\right)+t}
$$

\begin{tabular}{|c|c|c|}
\hline $\begin{array}{l}\text { Parameter } \\
\text { LICC }\end{array}$ & $\begin{array}{c}\text { Nominal T Structure } \\
\mathrm{X}_{1}=\mathrm{X}_{2}=-\mathrm{X}_{3}\end{array}$ & $\begin{array}{c}\text { Nominal } \prod \text { Structure } \\
X_{1}=X_{2}=-X_{3}\end{array}$ \\
\hline $\begin{array}{l}\text { Voltage } \\
\text { Gain }\end{array}$ & $\begin{array}{l}M=\frac{V_{2}}{V_{1}} \\
=\frac{X_{3}}{\left[X_{1} X_{2}+X_{2} X_{3}+X_{3} X_{1}\right] C+t\left(X_{1}+X_{3}\right)} \\
=\frac{t}{X_{2} C} @ \text { LICC }\end{array}$ & $M=\frac{t X_{2}}{X_{2} X_{3} C+t\left(X_{2}+X_{3}\right)}=\frac{t}{X_{3} C} @$ LICC \\
\hline $\begin{array}{l}\text { Current } \\
\text { Gain }\end{array}$ & $\mathrm{H}=\frac{\mathrm{I}_{2}}{\mathrm{I}_{1}}=\frac{\mathrm{X}_{3}}{\mathrm{X}_{2}+\mathrm{X}_{3}+(\mathrm{t} / \mathrm{C})}=\frac{\mathrm{X}_{\mathrm{C}} \mathrm{C}}{\mathrm{t}} @ \mathrm{VLICC}$ & $\mathrm{H}=\frac{\mathrm{X}_{1} \mathrm{X}_{2}}{\mathrm{X}_{1} \mathrm{X}_{2}+\mathrm{X}_{2} \mathrm{X}_{3}+(\mathrm{t} / \mathrm{C})\left(\mathrm{X}_{1}+\mathrm{X}_{2}+\mathrm{X}_{3}\right)}=\frac{\mathrm{CX}_{2}}{\mathrm{t}} @$ LICC \\
\hline $\begin{array}{l}\text { Load } \\
\text { Current }\end{array}$ & $\begin{array}{r}I_{2}=\frac{X_{1} X_{2}+X_{2} X_{3}+X_{3} X_{1}+(t / C)\left(X_{1}+X_{3}\right)}{V_{1}} \\
X_{2} @ \text { LICC }\end{array}$ & $\mathrm{I}_{2}=\frac{\mathrm{X}_{2} \mathrm{~V}_{1}}{\mathrm{X}_{2} \mathrm{X}_{3}+(\mathrm{t} / \mathrm{C})\left(\mathrm{X}_{2}+\mathrm{X}_{3}\right)}=\frac{\mathrm{V}_{1}}{\mathrm{X}_{3}} @$ LICC \\
\hline $\begin{array}{l}\text { Source } \\
\text { Current }\end{array}$ & $\begin{array}{l}=\frac{\mathrm{V}_{1}\left(\mathrm{X}_{2}+\mathrm{X}_{3}+(\mathrm{t} / \mathrm{C})\right)}{\mathrm{X}_{1} \mathrm{X}_{2}+\mathrm{X}_{2} \mathrm{X}_{3}+\mathrm{X}_{3} \mathrm{X}_{1}+(\mathrm{t} / \mathrm{C})\left(\mathrm{X}_{1}+\mathrm{X}_{3}\right)} \\
=\frac{\mathrm{V}_{1} \mathrm{t}}{\mathrm{X}_{2} \mathrm{X}_{3} \mathrm{C}} @ \text { LICC }\end{array}$ & $I_{1}=\frac{V_{1}\left[X_{1} X_{2}+X_{2} X_{3}+(t / C)\left(X_{1}+X_{2}+X_{3}\right)\right]}{X_{1}\left[X_{2} X_{3}+(t / C)\left(X_{2}+X_{3}\right)\right.}=\frac{t V_{1}}{X_{1} X_{3} C} @$ LICC \\
\hline Parameter & Ladder Structure-LS2 & $\begin{array}{c}\text { Branch Type Structure } \\
X A=X B=-(X C+X 3)\end{array}$ \\
\hline LICC & $\begin{array}{c}\mathrm{X}_{2}=-\mathrm{X}_{3} \text { and } \mathrm{X}_{4}=\frac{\mathrm{X}_{2} \mathrm{X}_{3}}{\mathrm{X}_{2}-\mathrm{X}_{1}} \\
\mathrm{tX}_{3}\end{array}$ & $\begin{array}{c}\text { Where } \mathrm{X}_{\mathrm{A}}=\frac{\mathrm{X}_{1} \mathrm{X}_{4}}{\mathrm{X}_{1}+\mathrm{X}_{2}+\mathrm{X}_{4}} ; \quad \mathrm{X}_{\mathrm{B}}=\frac{\mathrm{X}_{2} \mathrm{X}_{4}}{\mathrm{X}_{1}+\mathrm{X}_{2}+\mathrm{X}_{4}} \text { and } \\
\mathrm{X}_{\mathrm{C}}=\frac{\mathrm{X}_{1} \mathrm{X}_{2}}{\mathrm{X}_{1}+\mathrm{X}_{2}+\mathrm{X}_{4}} \\
\mathrm{t}\left(\mathrm{X}_{\mathrm{C}}+\mathrm{X}_{3}\right)\end{array}$ \\
\hline $\begin{array}{l}\text { Voltage } \\
\text { Gain }\end{array}$ & $\begin{array}{c}{\left[\mathrm{X}_{2}^{2}+2 \mathrm{X}_{2} \mathrm{X}_{3}+\mathrm{X}_{3} \mathrm{X}_{1}\right] \mathrm{C}+\mathrm{t}\left(\mathrm{X}_{2}+\mathrm{X}_{3}\right)} \\
=\frac{\mathrm{t}}{\mathrm{X}_{2} \mathrm{C}} @ \mathrm{LICC}\end{array}$ & $\begin{array}{c}M=\frac{\left.X_{A} X_{B}+X_{B}\left(X_{C}+X_{3}\right)+X_{A}\left(X_{C}+X_{3}\right)\right] C+t\left(X_{A}+X_{C}+X_{3}\right)}{X_{B} C} @ \text { LICC }\end{array}$ \\
\hline $\begin{array}{l}\text { Current } \\
\text { Gain }\end{array}$ & $\mathrm{H}=\frac{\mathrm{X}_{3}}{\mathrm{X}_{2}+\mathrm{X}_{3}+(\mathrm{t} / \mathrm{C})}=\frac{\mathrm{X}_{3} \mathrm{C}}{\mathrm{t}} @ \mathrm{LICC}$ & $\mathrm{H}=\frac{\mathrm{X}_{\mathrm{C}}+\mathrm{X}_{3}}{\mathrm{X}_{\mathrm{B}}+\mathrm{X}_{\mathrm{C}}+\mathrm{X}_{3}+(\mathrm{t} / \mathrm{C})}=\frac{\mathrm{X}_{3} \mathrm{C}}{\mathrm{t}} @ \mathrm{LICC}$ \\
\hline $\begin{array}{l}\text { Load } \\
\text { Current }\end{array}$ & $I_{2}=\frac{V_{1} X_{3} C}{C X_{2}^{2}+2 X_{2} X_{3} C+t\left(X_{2}+X_{3}\right)}=\frac{V_{1}}{X_{2}} @$ LICC & $\begin{array}{l}I_{2}=\frac{V_{1}\left(X_{C}+X_{3}\right) C}{\left[X_{A} X_{B}+X_{B}\left(X_{C}+X_{3}\right)+X_{A}\left(X_{C}+X_{3}\right)\right] C+t\left(X_{A}+X_{C}+X_{3}\right)} \\
=\frac{V_{1}}{X_{B}} @ \text { LICC }\end{array}$ \\
\hline $\begin{array}{l}\text { Source } \\
\text { Current }\end{array}$ & $\begin{array}{r}\mathrm{I}_{1}=\frac{\mathrm{V}_{1}\left(\mathrm{X}_{2}+\mathrm{X}_{3}+(\mathrm{t} / \mathrm{C})\right)}{\mathrm{X}_{2}^{2}+2 \mathrm{X}_{2} \mathrm{X}_{3}+(\mathrm{t} / \mathrm{C})\left(\mathrm{X}_{2}+\mathrm{X}_{3}\right)} \\
=\frac{t V_{1}}{\mathrm{X}_{2} \mathrm{X}_{3} \mathrm{C}} @ \text { LICC }\end{array}$ & $\begin{array}{l}\mathrm{I}_{1} \\
=\frac{\mathrm{V}_{1}\left(\mathrm{X}_{\mathrm{B}}+\mathrm{X}_{\mathrm{C}}+\mathrm{X}_{3}+(\mathrm{t} / \mathrm{C})\right)}{\mathrm{X}_{\mathrm{A}} \mathrm{X}_{\mathrm{B}}+\mathrm{X}_{\mathrm{B}}\left(\mathrm{X}_{\mathrm{C}}+\mathrm{X}_{3}\right)+\mathrm{X}_{\mathrm{A}}\left(\mathrm{X}_{\mathrm{C}}+\mathrm{X}_{3}\right)+(\mathrm{t} / \mathrm{C})\left(\mathrm{X}_{\mathrm{A}}+\mathrm{X}_{\mathrm{C}}+\mathrm{X}_{3}\right)} \\
=\frac{\mathrm{V}_{1} \mathrm{t}}{\mathrm{X}_{\mathrm{B}} \mathrm{X}_{\mathrm{C}} \mathrm{C}} @ \text { LICC }\end{array}$ \\
\hline
\end{tabular}

Similar analysis is done to find expression for all time dependent parameters (load current, source current, voltage gain and current gain) of other topologies. Summary of governing equations is presented in Table1.

Table 1. Parameter Summary of CLRC Structures 


\section{DESIGN AND MODEL VERIFICATION}

With the readily available mathematical model in section 2 , this section now proceeds to build a three stage constant current charging setup. Fig 3 below presents the basic block diagram of charger.

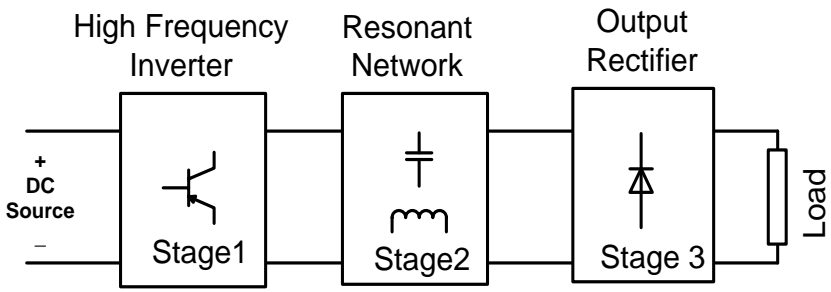

Figure 3. Block diagram of proposed CC Charger.

The H-Bridge inverter at stage 1 converts DC to high frequency (square wave) AC. RC at stage 2 extracts the fundamental of the square wave and is responsible for facilitating constant current at load. Output rectifier at stage 3 converts the high frequency AC back to DC and charges the load capacitor. Investigating a suitable RC topology for this purpose is the immediate objective of paper. Following methodology was framed to accomplish this.

i. All the 25 CLRCs listed in Fig1 are designed to a common specification.

ii. Simulink model is built in MATLAB to verify the design.

iii. Effectiveness of topologies is judged by accounting few performance parameters like M, H, $\mathrm{I}_{2}$, $\mathrm{I}_{1}$, etc and finally, a best topology for charging application is recommended.

iv. Findings are verified with a hardware prototype.

To start with, all the 25 CLRCs are designed to a common criterion of delivering $100 \mathrm{~mA}$ constant current to load. As it is highly difficult to show the analysis of all considered topologies, a general design procedure is demonstrated for the same LA7 topology. The complete schematic of CC charger using LA7 topology is presented in Fig4.

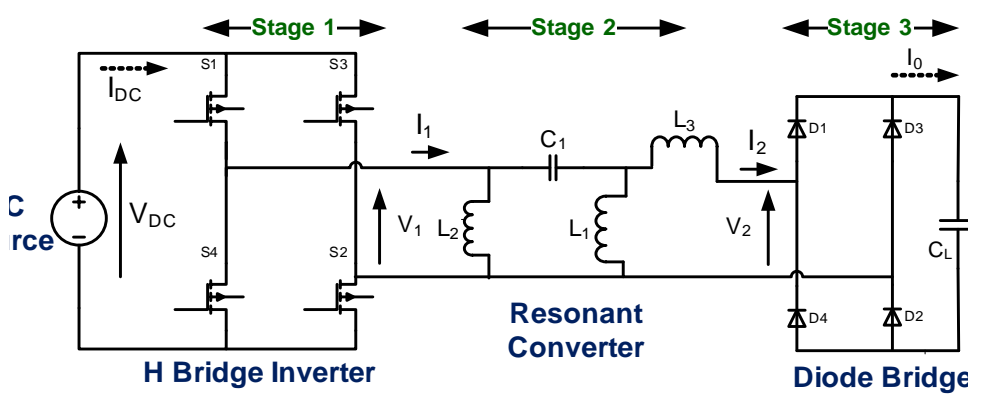

Figure 4. Schematic of CC Charger using LA7 Topology

Notations, specifications, design procedure, theoretical calculations, simulation results of developed of CC charger is given in following subsections.

\subsection{Notation and Specifications}

$\mathrm{I}_{0} \quad=$ Average Load Current/Charging Current $=100 \mathrm{~mA}$

$\mathrm{t}=$ Charging time $=50 \mathrm{~ms}$

$\mathrm{C}_{\mathrm{L}}=\mathrm{DC}$ load capacitor $=47 \mu \mathrm{F}$

$\mathrm{f}_{\mathrm{r}} \quad=$ Resonant Frequency $=25 \mathrm{kHz}$

$\mathrm{V}_{\mathrm{DC}}=\mathrm{DC}$ Source Voltage $=25 \mathrm{~V}$

$\mathrm{I}_{\mathrm{DC}}=$ DC Source current.

\subsection{Design Procedure and Theoretical Values}

$\mathrm{V}_{0}=$ Average Load Voltage $=\mathrm{tI}_{0} / \mathrm{C}=106.38 \mathrm{v}$

$\mathrm{I}_{2}=$ RMS Load current $=$ Form Factor $* \mathrm{I}_{0} \quad=1.11 * 100 \mathrm{~m}=111 \mathrm{~mA}$

$\omega_{\mathrm{o}}=$ Angular Resonant frequency $=2 \pi \mathrm{f}_{\mathrm{r}}=157 \mathrm{rad} / \mathrm{s}$

$\mathrm{V}_{1}=\mathrm{RMS}$ of fundamental voltage at $\mathrm{RC}=\frac{2 \sqrt{2} \mathrm{~V}_{\mathrm{DC}}}{\pi}=22.5 \mathrm{~V}$ 
$\mathrm{C}=$ Capacitor referred to $\mathrm{AC}$ side of rectifier $=\frac{\pi^{2} \mathrm{C}_{\mathrm{L}}}{8}=58 \mu \mathrm{F}$

Substituting $I_{2}$ and $V_{1}$ in equation (5) gives $L_{1}=1.29 \mathrm{mH}$

Substituting $\mathrm{L}_{1}$ in equation (2) will give magnitude of other resonant components and reactance as followed.

$\mathrm{L}_{1}=\mathrm{L}_{3}=1.29 \mathrm{mH} \Rightarrow \mathrm{X}_{2}=\mathrm{X}_{3}=202.63 \mathrm{j} \Omega, \mathrm{L}_{2}=0.645 \mathrm{mH} \Rightarrow \mathrm{X}_{4}=101.31 \mathrm{j} \Omega, \mathrm{C}_{1}=31.4 \mathrm{\eta F} \Rightarrow \mathrm{X}_{1}=.202 .63 \mathrm{j} \Omega$

From equation (3) - (6) $\mathrm{M}=$ Voltage gain $=\frac{\mathrm{t}}{\mathrm{X}_{1} \mathrm{C}}=4.255$,

$$
\begin{aligned}
& \mathrm{H}=\text { Current gain }=\frac{\mathrm{x}_{3} \mathrm{C}}{\mathrm{t}}=0.2351, \\
& \mathrm{I}_{1}=\text { RMS Source Current }=\frac{\mathrm{tv}_{1}}{\mathrm{x}_{1} \mathrm{X}_{3} \mathrm{C}}=472.1 \mathrm{~mA}
\end{aligned}
$$

\subsection{Verification by Simulation}

To verify the design, a MATLAB Simulink model is developed for the schematic shown in fig4 with the specifications already discussed. Alternately, plotting the time response for parameters mentioned in equations (3)-(6) using MATLAB coding offer a two step verification of proposed model. Results obtained by MATLAB Simulink and coding are presented in Fig 5 and Fig 6.

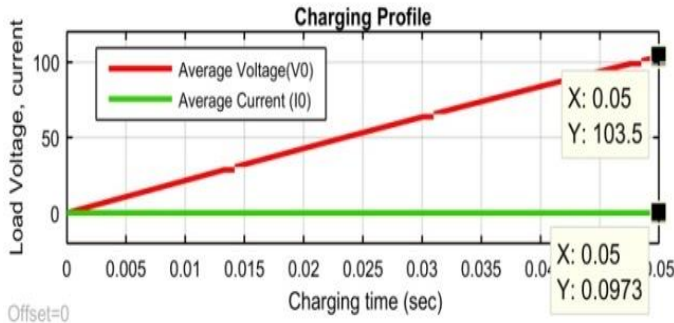

(a)

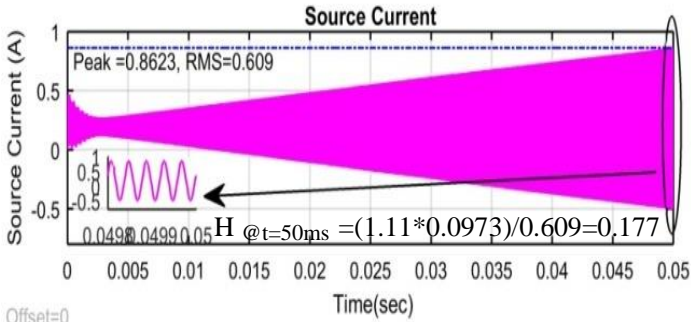

(b)

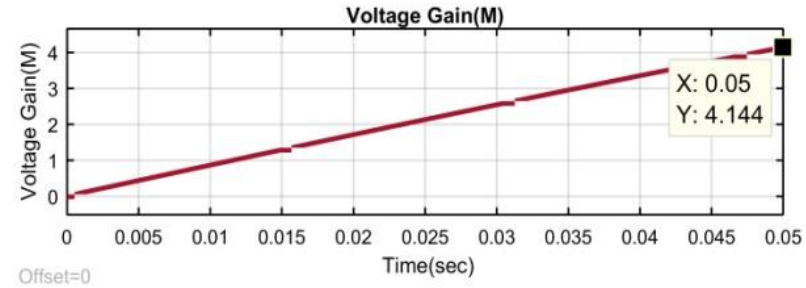

(c)

Figure 5. MATLAB Simulink output of CC Charger with LA7 topology (a) Charging profile, (b) Source current, (c) Voltage gain

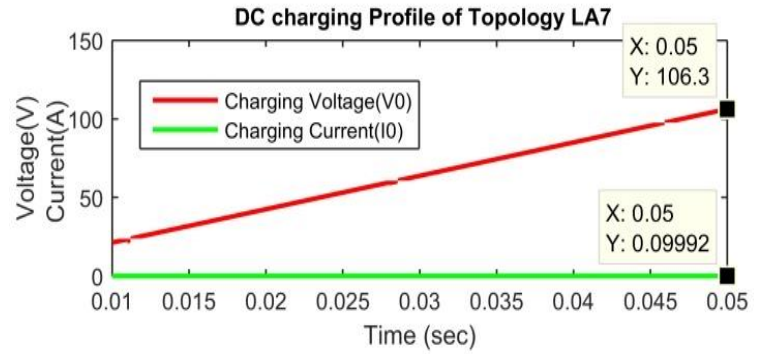

(a)

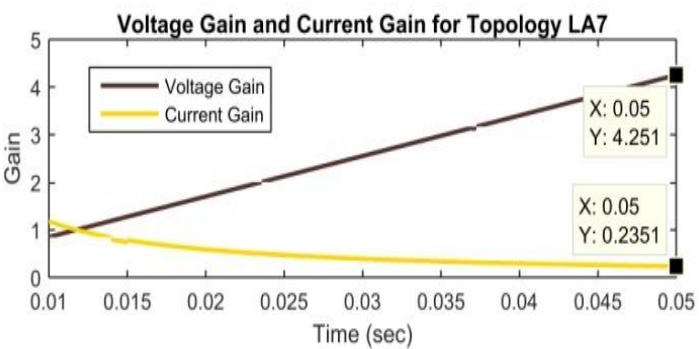

(c)

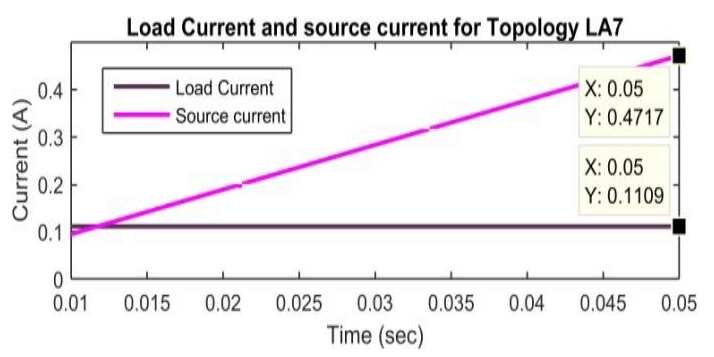

(b)

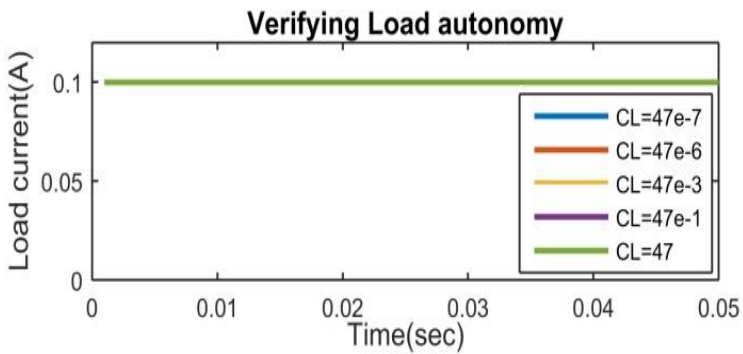

(d)

Figure 6.MATLAB Coding output of CC Charger with LA7 topology (a) Charging profile, (b) Load and Source current, (c) Gain, (d) Verifying Load Autonomy 
Fig 5(a) and 6(a) show that current pumped into the capacitor is constant and so a linearly increasing voltage profile is achieved. This verifies the basic functionality of CC Charger. Equation(6) claim that the current drawn by the resonant converter is proportional to the charging time. A growing pattern noticed in source current of Fig 5(b) and Fig 6(b) confirms the same. Gains observed from Fig 5(c) and 6(c) are in close agreement to the theoretical values. It is evident from Fig 6(d) that same charging current is delivered even if load capacitor is raised to 107 times. This validates the load autonomy, methodology and design procedure. With this motivation, the CC Charger is developed to chosen specifications using all the proposed topologies. Theoretical value of all the key parameters along with simulation results obtained by MATLAB coding and Simulink are consolidated in Table 2.

Table 2. Parameter Summary of All Topologies

\begin{tabular}{cllllll}
\hline $\mathbf{V}_{\mathbf{0}}(\mathbf{V})$ & $\mathbf{I}_{\mathbf{0}}(\mathbf{m A})$ & $\mathbf{I}_{\mathbf{2}}(\mathbf{m A})$ & $\mathbf{I}_{\mathbf{1}}$ Peak $(\mathbf{A})$ & $\mathbf{I}_{1} \mathbf{R} \mathbf{R} \mathbf{A}(\mathbf{m A})$ & $\mathbf{M}$ & $\mathbf{H}$ \\
Theoretical & Theoretical & Theoretical & Theoretical & Theoretical & Theoretical & Theoretical \\
S.No Topology 106.38 & $100 \mathrm{~mA}$ & $111 \mathrm{~mA}$ & 0.6677 & $472.1 \mathrm{~mA}$ & 4.255 & 0.2351
\end{tabular}

Simulink coding Simulink coding Simulink coding Simulink coding Simulink coding Simulink coding Simulink coding

\begin{tabular}{|c|c|c|c|c|c|c|c|c|c|c|c|c|c|c|}
\hline 1 & $\mathrm{~T} 1$ & 98.2 & 106.4 & 92.31 & 99.98 & 102.5 & 111 & 0.615 & 0.6675434 .8 & 472 & 3.99 & 4.253 & 0.2357 & 0.2351 \\
\hline 2 & $\mathrm{~T} 2$ & 102.9 & 106.4 & 96.72 & 99.98 & 107.4 & 111 & 0.664 & 0.6675469 .5 & 472 & 4.18 & 4.253 & 0.227 & 0.2351 \\
\hline 3 & $\mathrm{~T} 3$ & 98.85 & 106.4 & 92.92 & 99.98 & 103.1 & 111 & 0.617 & 0.6675436 .28 & 472 & 4.018 & 4.253 & 0.236 & 0.2351 \\
\hline 4 & $\mathrm{~T} 4$ & 96.57 & 106.4 & 90.77 & 100 & 100.8 & 111 & 0.55 & 0.6682388 .9 & 472.5 & 3.928 & 4.255 & 0.259 & 0.235 \\
\hline 5 & T5 & 101.4 & 106.4 & 95.31 & 100 & 105.8 & 111 & 0.585 & 0.6682413 .65 & 472.5 & 4.12 & 4.256 & 0.2557 & 0.235 \\
\hline 6 & T6 & 96.34 & 106.4 & 90.56 & 99.98 & 100.5 & 111 & 0.598 & 0.6675422 .84 & 472 & 3.92 & 4.253 & 0.2376 & 0.2351 \\
\hline 7 & $\mathrm{~T} 7$ & 91.28 & 106.4 & 85.8 & 99.98 & 95.24 & 111 & 0.528 & 0.6675373 .35 & 472 & 3.72 & 4.253 & 0.255 & 0.2351 \\
\hline 10 & $\mathrm{P} 1$ & 87.88 & 106.4 & 82.6 & 100 & 91.69 & 111 & 0.555 & 0.6682392 .44 & 472.5 & 3.516 & 4.256 & 0.233 & 0.235 \\
\hline 11 & $\mathrm{P} 2$ & 87.88 & 106.4 & 82.6 & 100 & 91.69 & 111 & 0.466 & 0.6682329 .51 & 472.5 & 3.514 & 4.256 & 0.278 & 0.235 \\
\hline 12 & $\mathrm{P} 3$ & 91.83 & 106.4 & 86.32 & 100 & 95.81 & 111 & 0.51 & 0.6682360 .62 & 472.5 & 3.673 & 4.255 & 0.265 & 0.235 \\
\hline 13 & $\mathrm{P} 4$ & 87.88 & 106.4 & 82.6 & 100 & 91.69 & 111 & 0.826 & 0.6682584 .07 & 472.5 & 3.516 & 4.256 & 0.156 & 0.235 \\
\hline 14 & P5 & 85.62 & 106.4 & 80.48 & 100 & 89.34 & 111 & 0.609 & 0.6682430 .62 & 472.5 & 3.424 & 4.255 & 0.207 & 0.235 \\
\hline 19 & LA3 & 102.4 & 106.3 & 96.23 & 99.92 & 106.8 & 110.9 & 0.96 & 0.6675678 .82 & 472 & 4.16 & 4.251 & 0.157 & 0.235 \\
\hline 20 & LA4 & 95.75 & 106.4 & 90.01 & 99.98 & 99.91 & 111 & 0.627 & 0.6675443 .35 & 472 & 3.896 & 4.253 & 0.225 & 0.2351 \\
\hline 21 & LA5 & 90.79 & 106.5 & 85.34 & 100.1 & 94.73 & 111.1 & 0.71 & 0.6682502 .04 & 472.5 & 3.696 & 4.258 & 0.188 & 0.2351 \\
\hline 22 & LA6 & 85.04 & 106.4 & 79.94 & 99.98 & 88.73 & 111 & 0.487 & 0.6675344 .36 & 472 & 3.468 & 4.253 & 0.257 & 0.2351 \\
\hline 23 & LA7 & 103.5 & 106.3 & 97.28 & 99.92 & 108 & 110.9 & 0.862 & 0.6671609 .52 & 471.7 & 4.204 & 4.251 & 0.177 & 0.2351 \\
\hline 24 & LA8 & 91.65 & 106.4 & 86.15 & 100 & 95.63 & 111 & 0.618 & 0.6682436 .99 & 472.5 & 3.728 & 4.256 & 0.218 & 0.235 \\
\hline 25 & BT1 & 100.8 & 106.3 & 94.76 & 99.92 & 105.2 & 110.9 & 0.68 & 0.6668480 .83 & 471.5 & 4.096 & 4.251 & 0.218 & 0.2352 \\
\hline
\end{tabular}

Though all the topologies are designed to same specifications, a practical model tend to observe a marginal deviation from the design because of various topological influences like, circulating currents, mutual induction, parasitic effects resulted from geometrical arrangement, etc. Hence the degree of co-ordination between the theoretical and simulated parameter values differed with topology.

It is observed that P2 has the ability to drive minimum current through inverter switches and so it is recommended for applications where rating of switch and heat sink requirement should be minimum. LA7 and P2 topologies have maximum voltage and current gain respectively. Thus they are recommended for high gain converters and induction heating applications. A fast charging circuitry requires non-lossy topology which can effectively transfer current to load. It is seen that LA7 delivers maximum load current and so it considered as best fit for charging purpose.

\section{EXPERIMENTAL VALIDATION AND RESULT ANALYSIS}

Section 3 of paper concluded that LA7 topology is best choice for charging application. Hence a hardware prototype is built to validate the claim and verify the theoretical \& simulated performances obtained so far. Complete hardware set up of CC charger comprising of the digital control unit, H-Bridge inverter, LA7 RC, Diode bridge rectifier, etc is shown in Fig 7. 


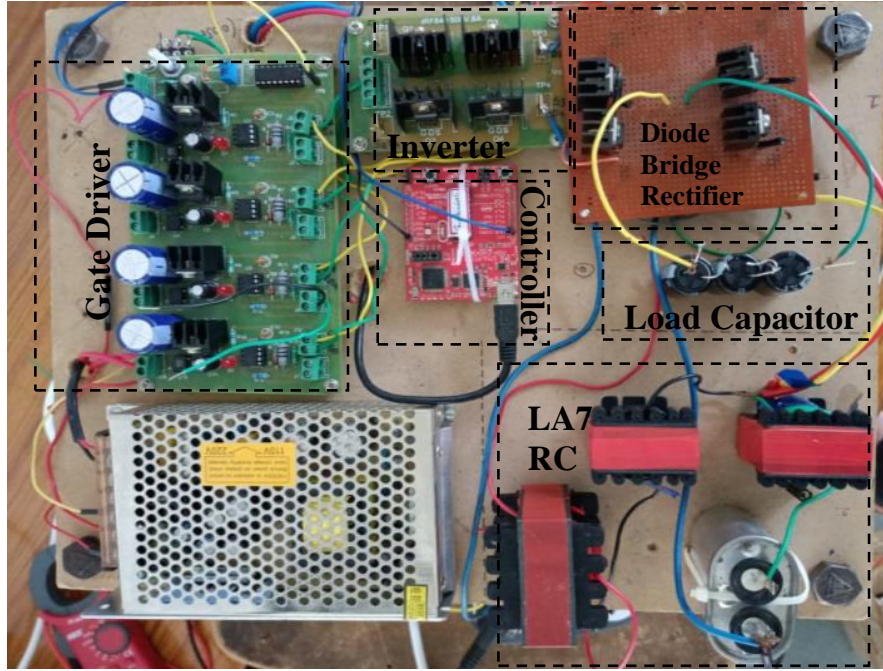

Figure 7. Hardware prototype of CC Charger with LA7 topology

The digital control circuit consists of MSP430G2553 Texas launch pad to generate the timing reference for KA3525 PWM controller IC. To match the GATE charge requirements of IRF840 MOSFET switches in inverter, the control signals generated by PWM IC is boosted using HCPLA3120 gate drive optocoupler. Constrained by market availability, the $31.4 \mathrm{nF}$ resonant capacitor is replaced by $33 \mathrm{nF}$ capacitor. To maintain the resonant frequency at $25 \mathrm{kHz}$, three inductors of LA7 RC are revised to $1.23 \mathrm{mH}, 1.23 \mathrm{mH}$ and $2.46 \mathrm{mH}$. To reduce the hysteresis losses at high frequency of operation, EE4220 ferrite core is chosen to wind the inductor. RHRP30120 hyper fast recovery diode with recovery time $<65 \mathrm{~ns}$ is used to build the diode bridge rectifier. A $400 \mathrm{~V}$ electrolytic capacitor in multiples of $80 \mu \mathrm{F}$ is considered as load capacitor. Charging voltage and source current $\left(\mathrm{I}_{11}, \mathrm{I}_{12}, \mathrm{I}_{13}\right)$ for different load capacitors captured by the dual channel oscilloscope for a common DC input voltage (VDC) 0f $3.5 \mathrm{~V}$ is shown in Fig8.

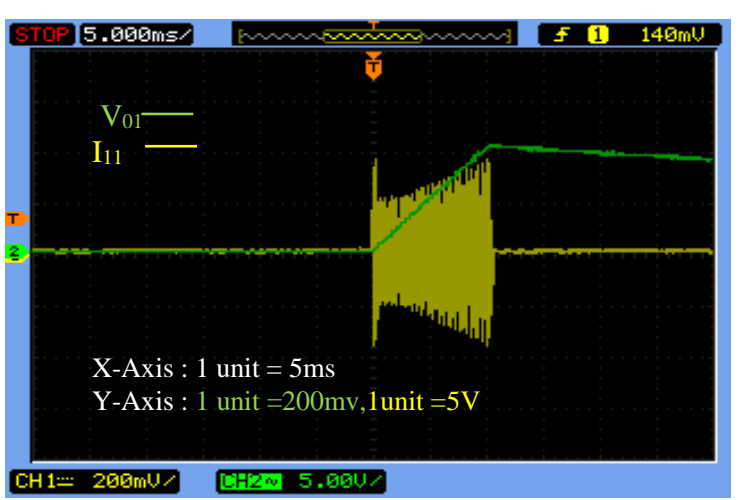

(a)

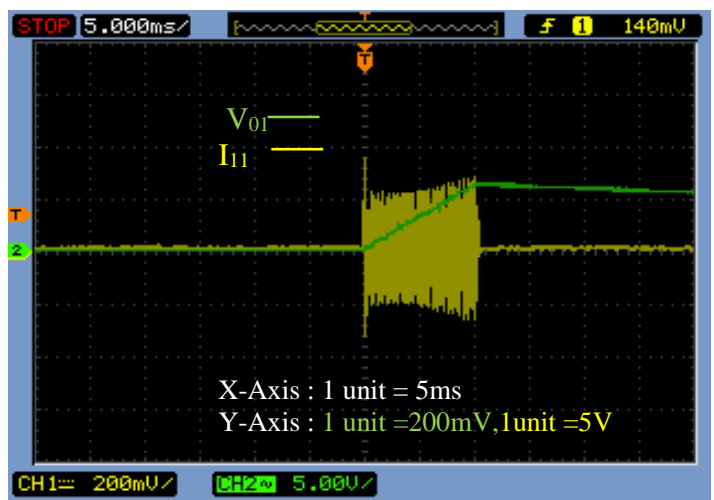

(b)

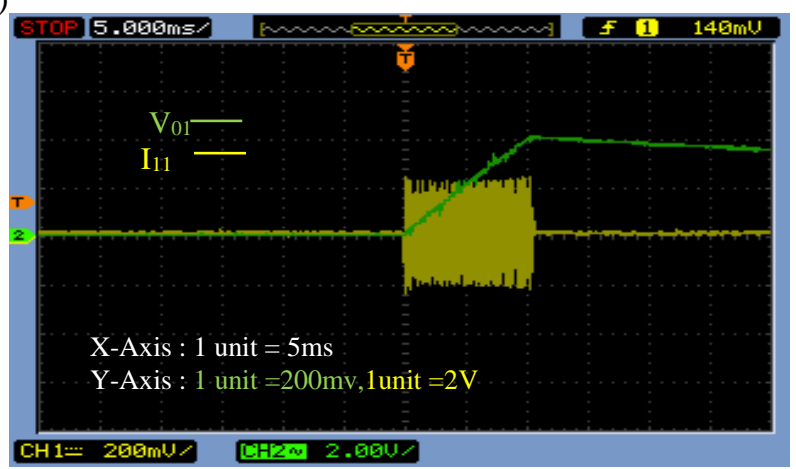

(c)

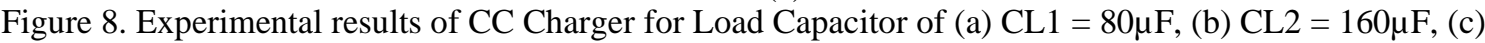
$\mathrm{CL} 3=240 \mu \mathrm{F}$ 
The charging profile of CC charger for a load capacitors of CL1 $=80 \mu \mathrm{F}, \mathrm{CL} 2=160 \mu \mathrm{F}$ and CL3 $=$ $240 \mu \mathrm{F}$ is presented in Fig 8(a), Fig8(b) and Fig8(c) respectively. As anticipated, a linear load voltage and growing source current patterns are clearly noticed for all the load condition. The magnitude of load voltage at the end of charging interval ( $\mathrm{t}$ ) of $10 \mathrm{~ms}$ observed for $\mathrm{C}_{\mathrm{L} 1}, \mathrm{C}_{\mathrm{L} 2}$ and $\mathrm{C}_{\mathrm{L} 3}$ is $\mathrm{V}_{01}=12 \mathrm{v}, \mathrm{V}_{02}=6 \mathrm{v}$ and $\mathrm{V}_{03}=4.1 \mathrm{v}$ respectively. The average load current delivered to these capacitors are evaluated using the expression $\mathrm{i}_{0}=$ $\mathrm{C} \frac{\mathrm{dV_{0 }}}{\mathrm{dt}}$ and are found to be $\mathrm{I}_{01}=96 \mathrm{~mA}, \mathrm{I}_{02}=96 \mathrm{~mA}$ and $\mathrm{I}_{03}=98 \mathrm{~mA}$. It is observed that the charger setup is able to deliver approximately the same load current irrespective of load. This validates the design and concept of $\mathrm{CC}$ Charger proposed in paper. Efficiency of the charger is ratio of dc power delivered at load $\left(\mathrm{V}_{\mathrm{O}} \mathrm{I}_{\mathrm{O}}\right)$ to the power drawn from DC source $\left(\mathrm{V}_{\mathrm{DC}} \mathrm{I}_{\mathrm{DC}}\right)$. Efficiency calculated by this formula for the 3 load capacitors is $94.2 \%$, $94.9 \%$ and $95.2 \%$.

\section{CONCLUSION}

This paper emphasized the importance of load independent constant current in charging applications and explored the role of higher order capacitive loaded resonant converters to achieve it. About 25 resonant converter topologies are reported for same. All the reported converter topologies are modeled mathematically, verified by simulation, and scrutinized to brief out the individual characteristics. The study carried out in this paper will helps researchers and designers to have a quick overview of various CLRC topologies and assist them in choosing the right topology for their application. Apart from figuring out the general characteristics of individual topologies, this paper also explored a novel CLRC topology called LA7 for constant current charging application. To demonstrate and verify the basic operation of LICC, a bench top hardware prototype has been built. An excellent co-ordination is noticed between the measured and experimental values of different performance parameters such as LICC, current gain, voltage gain and source peak current. Developing an intelligent $\mathrm{CC}$ charger which is driven by a feedback from artificial intelligence based battery health monitoring system could be the future prospective of the study.

\section{REFERENCES}

[1] S. Hu, X. Li and A. K. S. Bhat, "Operation of a Bidirectional Series-Resonant Converter With Minimized Tank Current and Wide ZVS Range," in IEEE Transactions on Power Electronics, vol. 34, no. 1, pp. 904-915, Jan. 2019 , doi: 10.1109/TPEL.2018.2818145.

[2] P. Naresh, A. Patel and A. Sharma, Conducted noise analysis and protection of $45 \mathrm{~kJ} / \mathrm{s}, \pm 50 \mathrm{kV}$ capacitor charging power supply when interfaced with repetitive Marx based pulse power system, Rev. Sci. Instrum. 86 (2015) 094701.

[3] H. -P. Park, S. Jeong, M. Kim, J. Kim and J. -H. Jung, "APWM Resonant Converter with SST for EMI Filter Size Reduction," 2019 10th International Conference on Power Electronics and ECCE Asia (ICPE 2019 - ECCE Asia), 2019, pp. 2886-2891, doi: 10.23919/ICPE2019-ECCEAsia42246.2019.8797195.

[4] P. Naresh, C. Hitesh, A. Patel, T. Kolge, Archana Sharma and K.C. Mittal, "Analysis and development of fourth order LCLC resonant based capacitor charging power supply for pulse power applications", Rev. Sci. Instrum, vol. 84, pp. 084706, 2013.

[5] G.Pandeswara and N.Pasula."Investigation through analytical studies and experimental validation of ladder type resonant converter based constant current charger $(>20 \mathrm{~kW})$ for charging applications", Journal of Instrumentation, vol 16, febrauary2021, doi : 10.1088/1748-0221/16/02/P02032N.

[6] M. Khatua et al., "High-Performance Megahertz-Frequency Resonant DC-DC Converter for Automotive LED Driver Applications," in IEEE Transactions on Power Electronics, vol. 35, no. 10, pp. 10396-10412, Oct. 2020, doi: 10.1109/TPEL.2020.2974970.

[7] Y. Li, S. Shao, H. Chen, J. Zhang and K. Sheng, "High-gain high-efficiency IPOS LLC converter with coupled transformer and current sharing capability," in CPSS Transactions on Power Electronics and Applications, vol. 5, no. 1, pp. 63-73, March 2020, doi: 10.24295/CPSSTPEA.2020.00006.

[8] R. P. Eldho, A. Chhabra and C. P. Ragasudha, "An Overview on Single/Multi Output Isolated Resonant Converter Topologies for Vehicular applications," 2021 7th International Conference on Advanced Computing and Communication Systems (ICACCS), 2021, pp. 1569-1572, doi: 10.1109/ICACCS51430.2021.9441891.

[9] G. K. Gaidhane and A. S. Sindekar, "Performance of dual-bridge high frequency resonant DC/DC converter for energy storage application," 2016 International Conference on Energy Efficient Technologies for Sustainability (ICEETS), 2016, pp. 400-405, doi: 10.1109/ICEETS.2016.7583788.

[10] K. S. Prasad and N. Lakshminarasamma, "Effect of parasitics in high voltage bipolar flyback converter for lightly loaded resistive loads," 2017 IEEE International Conference on Signal Processing, Informatics, Communication and Energy Systems (SPICES), 2017, pp. 1-6, doi: 10.1109/SPICES.2017.8091331.

[11] M. Khatua et al., "High-Performance Megahertz-Frequency Resonant DC-DC Converter for Automotive LED Driver Applications," in IEEE Transactions on Power Electronics, vol. 35, no. 10, pp. 10396-10412, Oct. 2020, doi: 10.1109/TPEL.2020.2974970.

[12] Geethanjali Pandeswara, Naresh Pasula, and Geshma Kumari R ,"A multipurpose power supply for constant current, constant voltage and constant power applications", Review of Scientific Instruments 92, 114706 (2021) https://doi.org/10.1063/5.0054343 
[13] M. Srivastava, P. S. Tomar and A. K. Verma, "Implementation and Design Steps for Resonant DC-DC Converter in Vehicular Applications," 2020 IEEE International Conference on Power Electronics, Smart Grid and Renewable Energy (PESGRE2020), 2020, pp. 1-5, doi: 10.1109/PESGRE45664.2020.9070415.

[14] J. Deng, S. Li, S. Hu, C. C. Mi and R. Ma, "Design Methodology of LLC Resonant Converters for Electric Vehicle Battery Chargers," in IEEE Transactions on Vehicular Technology, vol. 63, no. 4, pp. 1581-1592, May 2014, doi: 10.1109/TVT.2013.2287379.

[15] W. Xichuan, D. Huan and Z. Ting, "A Rail-To-Rail Op-Amp with Constant Gm Using Current Switches," 2007 International Symposium on High Density packaging and Microsystem Integration, 2007, pp. 1-3, doi: 10.1109/HDP.2007.4283626.

[16] D. Schmitt and T. S. Fiez, "A low voltage CMOS current source," Proceedings of 1997 International Symposium on Low Power Electronics and Design, 1997, pp. 110-113, doi: 10.1145/263272.263301.

[17] Y. -S. Noh, D. Joo, B. J. Hyon, J. S. Park, J. -H. Kim and J. -H. Choi, "Development of 3-phase Current-fed Dual Active Bridge Converter for Bi-Directional Battery Charger Application," 2020 IEEE Energy Conversion Congress and Exposition (ECCE), 2020, pp. 2287-2290, doi: 10.1109/ECCE44975.2020.9236393.

[18] C. K. R. Reddy, S. Porpandiselvi and V. K. Satyakar Veeramallu, "Input Controlled Series-Resonant Converter for LED Lighting Application," 2018 3rd International Conference on Communication and Electronics Systems (ICCES), 2018, pp. 608-612, doi: 10.1109/CESYS.2018.8724015.

[19] J. Mućko, "Parallel resonant inverter with auxiliary AC/DC converter used for induction heating," 2011 7th International Conference-Workshop Compatibility and Power Electronics (CPE), 2011, pp. 415-419, doi: 10.1109/CPE.2011.5942271.

[20] J. Zeng, G. Zhang, S. S. Yu, B. Zhang and Y. Zhang, "LLC resonant converter topologies and industrial applications - A review," in Chinese Journal of Electrical Engineering, vol. 6, no. 3, pp. 73-84, Sept. 2020, doi: 10.23919/CJEE.2020.000021.

[21] J. Koscelnik, M. Frivaldsky, M. Prazenica and R. Mazgut, "A review of multi-elements resonant converters topologies," 2014 ELEKTRO, 2014, pp. 312-317, doi: 10.1109/ELEKTRO.2014.6848909.

[22] J. C. S. Woo, S. Wong, S. Verdonckt-Vanderbroek, P. Ko, K. Terrill and P. K. Vasudev, "Lateral npn bipolar transistor for high current gain applications at reduced temperatures," Proceedings of the Bipolar Circuits and Technology Meeting, 1989, pp. 152-155, doi: 10.1109/BIPOL.1989.69480.

[23] J. F. Aschner, C. A. Bittmann, W. F. J. Hare and J. J. Kleimack, "A silicon medium-power transistor for high-current high-speed switching applications," in IRE Transactions on Electron Devices, vol. 7, no. 4, pp. 251-256, Oct. 1960, doi: 10.1109/T-ED.1960.14689.

[24] D. Prasertsom and W. Tangsrirat, "Current gain controlled CFTA and Its application to resistorless quadrature oscillator," 2012 9th International Conference on Electrical Engineering/Electronics, Computer, Telecommunications and Information Technology, 2012, pp. 1-4, doi: 10.1109/ECTICon.2012.6254271.

[25] P. GEETHANJALI and P. NARESH, "Effect of Higher Order Resonant Converter Topology nn DC charging Application and Hardware Implementation," 2020 International Conference on Power Electronics \& IoT Applications in Renewable Energy and its Control (PARC), 2020, pp. 1-7, doi: 10.1109/PARC49193.2020.236546.

[26] N. Pasula, A. Patel, T. Kolge, C. Hitesh, A. Sharma and K. C. Mittal, "Comparative analysis of 2nd and 4th order resonant based capacitor charging power supplies," 2014 IEEE International Power Modulator and High Voltage Conference (IPMHVC), 2014, pp. 607-610, doi: 10.1109/IPMHVC.2014.7287349.

[27] J. P. Agrawal and C. Q. Lee, "Decomposition of circuit modes in high order resonant converters," Proceedings of the 32nd Midwest Symposium on Circuits and Systems,, 1989, pp. 792-795 vol.2, doi: 10.1109/MWSCAS.1989.101974.

[28] X. Ma, P. Wang, H. Bi and Z. Wang, "A Bidirectional LLCL Resonant DC-DC Converter With Reduced Resonant Tank Currents and Reduced Voltage Stress of the Resonant Capacitor," in IEEE Access, vol. 8, pp. 125549-125564, 2020, doi: 10.1109/ACCESS.2020.3007638.

[29] M. Borage, K. V. Nagesh, M. S. Bhatia and S. Tiwari, "Resonant Immittance Converter Topologies," in IEEE Transactions on Industrial Electronics, vol. 58, no. 3, pp. 971-978, March 2011, doi: 10.1109/TIE.2010.2047835.

[30] Chin Chang, "On the singularities in higher order resonant converters," in IEEE Transactions on Aerospace and Electronic Systems, vol. 38, no. 4, pp. 1412-1415, Oct. 2002, doi: 10.1109/TAES.2002.1145766. 